\title{
Complete genome sequence of Leadbetterella byssophila type strain $\left(4 \mathrm{M} 15^{\mathrm{T}}\right)$
}

\author{
Birte Abt ${ }^{1}$, Hazuki Teshima ${ }^{2,3}$, Susan Lucas ${ }^{2}$, Alla Lapidus ${ }^{2}$, Tijana Glavina Del Rio ${ }^{2}$, Matt \\ Nolan' ${ }^{2}$, Hope Tice' ${ }^{2}$ Jan-Fang Cheng ${ }^{2}$, Sam Pitluck ${ }^{2}$, Konstantinos Liolios ${ }^{2}$, Ioanna Pagani' ${ }^{2}$, \\ Natalia Ivanova ${ }^{2}$, Konstantinos Mavromatis ${ }^{2}$, Amrita Pati' ${ }^{2}$, Roxane Tapia ${ }^{2,3}$, Cliff Hann $^{2,3}$, \\ Lynne Goodwin ${ }^{2,3}$, Amy Chen ${ }^{4}$, Krishna Palaniappan ${ }^{4}$, Miriam Land ${ }^{2,5}$, Loren Hauser ${ }^{2,5}$, \\ Yun-Juan Chang ${ }^{2,5}$, Cynthia D. Jeffries ${ }^{2,5}$, Manfred Rohde ${ }^{6}$, Markus Göker ${ }^{1}$, Brian J. Tindall' \\ John C. Detter ${ }^{2,3}$, Tanja Woyke ${ }^{2}$, James Bristow ${ }^{2}$, Jonathan A. Eisen ${ }^{2,7}$, Victor Markowitz ${ }^{4}$, \\ Philip Hugenholtz ${ }^{2,8}$, Hans-Peter Klenk ${ }^{1}$, and Nikos C. Kyrpides ${ }^{2 *}$ \\ ${ }^{1}$ DSMZ - German Collection of Microorganisms and Cell Cultures GmbH, Braunschweig, \\ Germany \\ ${ }^{2}$ DOE Joint Genome Institute, Walnut Creek, California, USA \\ ${ }^{3}$ Los Alamos National Laboratory, Bioscience Division, Los Alamos, New Mexico USA \\ ${ }^{4}$ Biological Data Management and Technology Center, Lawrence Berkeley National \\ Laboratory, Berkeley, California, USA \\ ${ }^{5}$ Lawrence Livermore National Laboratory, Livermore, California, USA \\ ${ }^{6} \mathrm{HZI}$ - Helmholtz Centre for Infection Research, Braunschweig, Germany \\ ${ }^{7}$ University of California Davis Genome Center, Davis, California, USA \\ ${ }^{8}$ Australian Centre for Ecogenomics, School of Chemistry and Molecular Biosciences, The \\ University of Queensland, Brisbane, Australia
}

*Corresponding author: Nikos C. Kyrpides

Keywords: non-motile, non-sporulating, aerobic, mesophile, Gram-negative, flexirubin, $\mathrm{Cy}$ tophagaceae, GEBA

Leadbetterella byssophila Weon et al. 2005 is the type species of the genus Leadbetterella of the family Cytophagaceae in the phylum Bacteroidetes. Members of the phylum Bacteroidetes are widely distributed in nature, especially in aquatic environments. They are of special interest for their ability to degrade complex biopolymers. L. byssophila occupies a rather isolated position in the tree of life and is characterized by its ability to hydrolyze starch and gelatine, but not agar, cellulose or chitin. Here we describe the features of this organism, together with the complete genome sequence, and annotation. L. byssophila is already the $16^{\text {th }}$ member of the family Cytophagaceae whose genome has been sequenced. The 4,059,653 bp long single replicon genome with its 3,613 protein-coding and 53 RNA genes is part of the Genomic Encyclopedia of Bacteria and Archaea project.

\section{Introduction}

Strain 4 M15 $^{\mathrm{T}}$ (= DSM $17132=$ JCM $16389=$ KACC 11308 ) is the type strain of the species Leadbetterella byssophila, which is the type species of the genus Leadbetterella. Currently L. byssophila is the only validly named species in this genus. The type strain was isolated by Weon et al. [1] from cottonwaste compost soil used as mushroom cultivation in Suwon, South Korea. L. byssophila is described as aerobic, rod shaped and non-motile. The species belongs to the Cytophaga-FlavobacteriumBacteroides (CFB) group, also known as the phylum Bacteroidetes [2], which comprises organisms associated with the degradation of complex poly- saccharides. The CFB group consists of many bacterial strains isolated from marine environments and hypersaline lakes; but only a few were isolated from other habitats such as soil. Various taxonomic treatments have placed L. byssophila either in the family 'Flexibacteraceae' or the family Cytophagaceae. This is most probably due to a number of nomenclatural problems. The family 'Flexibacteraceae' as outlined in TOBA7.7 [3] would include Cytophaga hutchinsonii, which is the type species of the genus Cytophaga, which in turn is the type of the family Cytophagaceae, a name that may not be replaced by the family name 
'Flexibacteraceae' as long as Cytophaga hutchinsonii is one of the included species. A similar problem arises with the placement of Spirosoma linguale in the higher taxonomic ranks and has been discussed previously [4]. Here we present a summary classification and a set of features for L. byssophila $4 \mathrm{M} 15^{\mathrm{T}}$, together with the description of the complete genomic sequencing and annotation.

\section{Classification and features}

L. byssophila $4 \mathrm{M} 15^{\mathrm{T}}$ is very isolated in the tree of life, with no other species allocated to the same genus and with the type strains of the members of the genus Emticicia [5,6] sharing the highest degree of 16S rRNA sequence identity (88.3-88.9\%) [7], followed by Sporocytophaga myxococcoides (85.2\%) [8] and Siphonobacter aquaeclarae (85.0\%) [9]. No other cultured strain belonging to the species or genus has been described. Only one 16S rRNA sequence from a moderately related (95\% sequence identity) uncultivated clone, W4S69 (GU560170), identified by $\mathrm{Xu}$ and colleagues in pharmaceutical wastewater biofilms, was reported in GenBank. Neither environmental screenings nor genomic surveys produced any sequence that could be linked to the species L. byssophila or the genus Leadbetterella, indicating that members of the species are not heavily represented in the so far screened habitats (status November 2010).

A representative genomic 16S rRNA sequence of $L$. byssophila $4 \mathrm{M} 15^{\mathrm{T}}$ was compared using NCBI BLAST under default settings (e.g., considering only the high-scoring segment pairs (HSPs) from the best 250 hits) with the most recent release of the Greengenes database [10] and the relative frequencies, weighted by BLAST scores, of taxa and keywords (reduced to their stem [11]) were determined. The five most frequent genera were Pedobacter (35.1\%), Flectobacillus (11.4\%), Leadbetterella (9.4\%), Algoriphagus (8.6\%) and Arcicella $(6.8 \%)$ (80 hits in total). Regarding the single hit to sequences from members of the species, the average identity within HSPs was $100.0 \%$, whereas the average coverage by HSPs was $97.9 \%$. Among all other species, the one yielding the highest score was 'Kaistomonas ginsengisoli', which corresponded to an identity of $92.2 \%$ and a HSP coverage of $49.8 \%$. The name 'Kaistomonas ginsengisoli' (strain Gsoil 085, AB245370) is also to be found in a number of publications [12-14], but that has since become the type strain of Emticicia ginsengisoli [6].
The highest-scoring environmental sequence was HM238135 ('structure full-scale air pig facility biofilter treating waste gas clone FF 92'), which showed an identity of $93.1 \%$ and a HSP coverage of $96.0 \%$. The five most frequent keywords within the labels of environmental samples which yielded hits were 'lake' (4.8\%), 'litholog/stream' (4.5\%), 'biofilm' (3.3\%), 'microbi' (2.9\%) and 'site' (2.5\%) (170 hits in total). The five most frequent keywords within the labels of environmental samples which yielded hits of a higher score than the highest scoring species were 'soil' (5.1\%), 'biofilm/oxid' (5.1\%), 'air, biofilt, facil, full-scal, pig, structur, treat, wast' (2.7\%), 'forest, ghat, ground, india, mangrov, nich, prokaryt, select, studi, swab, western' (2.7\%) and 'cold, spring' (2.6\%) (5 hits in total).

Figure 1 shows the phylogenetic neighborhood of $L$. byssophila $4 \mathrm{M}^{\mathrm{T}} \mathrm{T}^{\mathrm{T}}$ in a $16 \mathrm{~S}$ rRNA based tree. The sequences of the three 16S rRNA gene copies in the genome do not differ from each other, and do not differ from the previously published $16 \mathrm{~S}$ rRNA sequence (AY854022).

Cells of L. byssophila stain Gram-negative and are non-motile, rod shaped with a width of 0.6-0.9 $\mu \mathrm{m}$ and a length of 2-7 $\mu \mathrm{m}$ (Figure 2 and Table 1). Colonies are circular, 1-2 $\mathrm{mm}$ in diameter, smooth, light orange, shiny and convex with entire margin when grown on trypticase soy agar. After prolonged incubation colonies become dark orange. Strain $4 \mathrm{M} 15^{\mathrm{T}}$ grows under aerobic conditions at temperatures of $15-45^{\circ} \mathrm{C}$ and at a $\mathrm{pH}$ range of 6.0 8.0. The strain grows in the presence of $1 \%(\mathrm{w} / \mathrm{v})$ $\mathrm{NaCl}$, but not at 3\% $\mathrm{NaCl}$ [1]. Growth on carbohydrates (API 20NE) was observed for glucose, arabinose, mannose, $\mathrm{N}$-acetylglucosamine and maltose but not for mannitol. Strain $4 \mathrm{M} 15^{\mathrm{T}}$ was positive for indole production and $\beta$-galactosidase, and negative for nitrate reduction and arginine dihydrolase (API 20NE). Enzymatic activity was detected for alkaline phosphatase, leucine arylamidase, valine arylamidase, trypsin, acid phosphatase, naphtholAS-BI-phosphohydrolase, $\alpha$-glucosidase, $\beta$ glucosidase, $\mathrm{N}$-acetyl- $\beta$-glucosaminidase and $\alpha$ fucosidase; weak enzymatic activity was observed for $\alpha$-galactosidase and $\beta$-galactosidase (API ZYM). L. byssophila produces catalase and urease [1]. Whereas starch, gelatin, aesculin and tyrosine are hydrolyzed; agar, casein, cellulose and chitin are not. Strain $4 \mathrm{M} 15^{\mathrm{T}}$ is sensitive to ampicillin, carbencillin, lincomycin, streptomycin and tetracycline and shows resistance to benzylpenicillin, gentamicin, neomycin, oleandomycin and polymyxin B. 


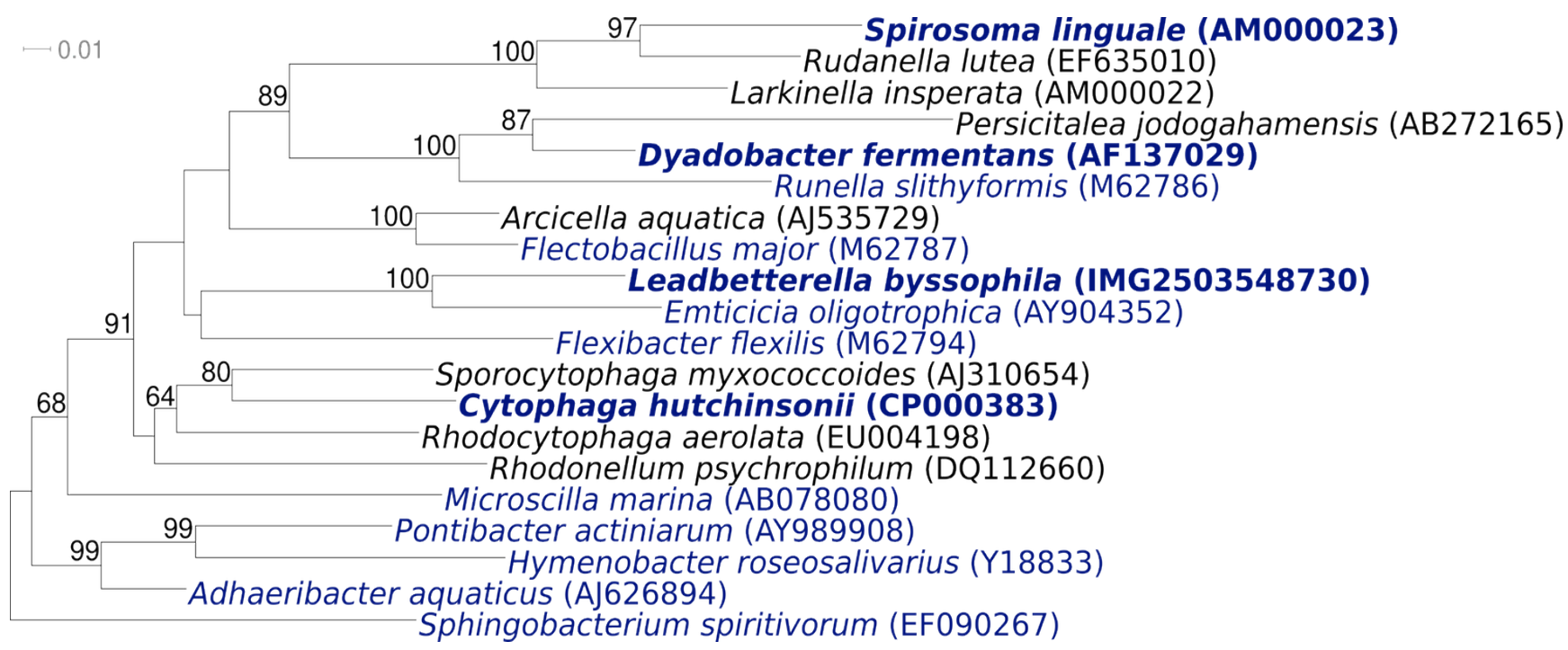

Figure 1. Phylogenetic tree highlighting the position of L. byssophila relative to the type strains of the other genera within the family Cytophagaceae. The tree was inferred from 1,340 aligned characters $[15,16]$ of the $16 \mathrm{~S}$ rRNA gene sequence under the maximum likelihood criterion [17] and rooted with the type strain of the closely related family Sphingobacteriaceae. The branches are scaled in terms of the expected number of substitutions per site. Numbers above branches are support values from 900 bootstrap replicates [18] if larger than $60 \%$. Lineages with type strain genome sequencing projects registered in GOLD [19] are shown in blue, published genomes in bold $[4,20,21]$.

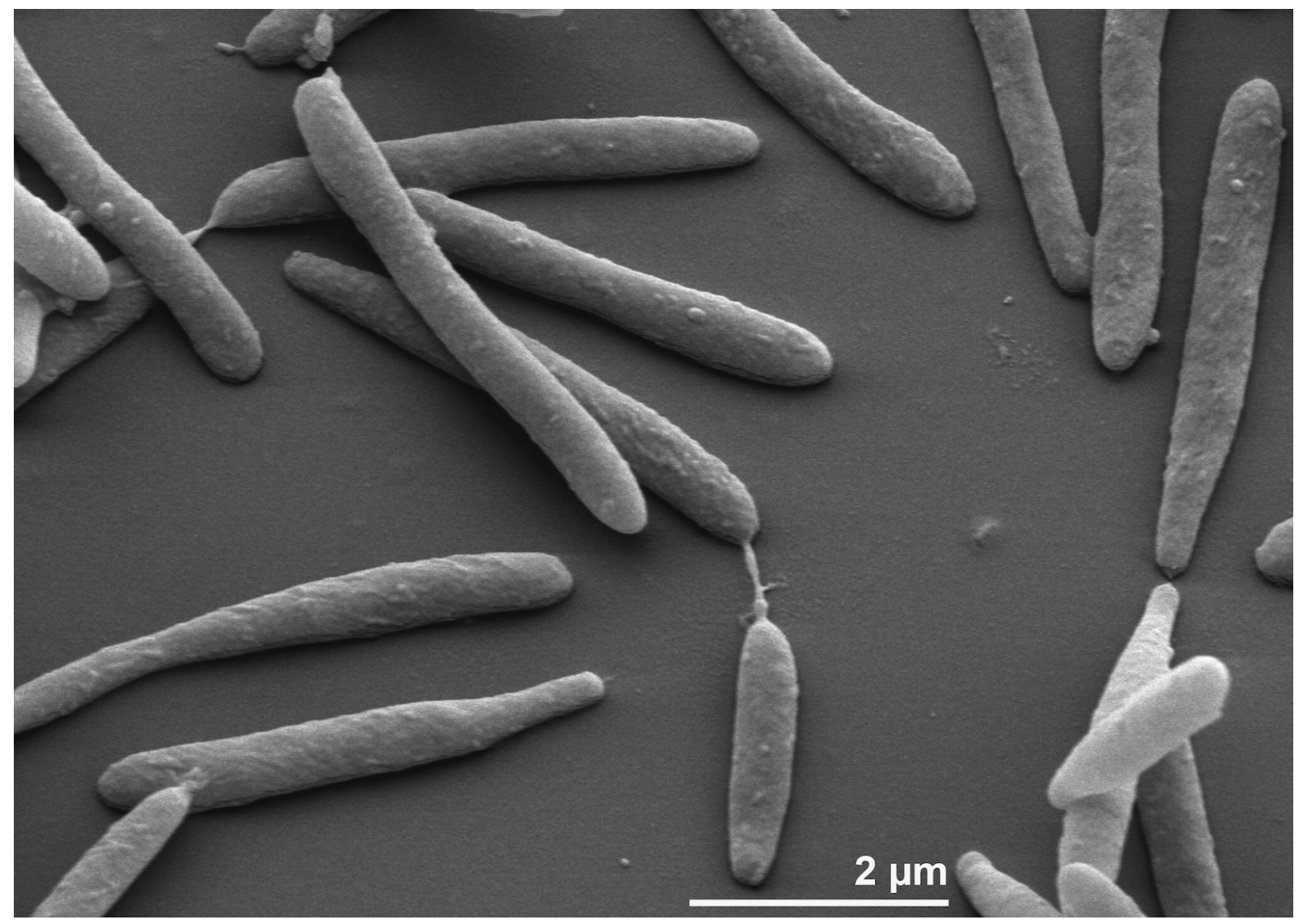

Figure 2. Scanning electron micrograph of L. byssophila $4 \mathrm{M} 15^{\mathrm{T}}$ 
Table 1. Classification and general features of L. byssophila according to the MIGS recommendations [22].

\begin{tabular}{|c|c|c|c|}
\hline MIGS ID & Property & Term & Evidence code \\
\hline & \multirow{8}{*}{ Current classification } & Domain Bacteria & TAS [23] \\
\hline & & Phylum Bacteroidetes & TAS [24] \\
\hline & & Class Cytophagia & TAS [25] \\
\hline & & Order Sphingobacteriales & TAS [24] \\
\hline & & Family Cytophagaceae & TAS $[25,26]$ \\
\hline & & Genus Leadbetterella & TAS [1] \\
\hline & & Species Leadbetterella byssophila & TAS [1] \\
\hline & & Type strain 4M15 & TAS [1] \\
\hline & Gram stain & negative & TAS [1] \\
\hline & Cell shape & rod-shaped & TAS [1] \\
\hline & Motility & non-motile & TAS [1] \\
\hline & Sporulation & non-sporulating & TAS [1] \\
\hline & Temperature range & mesophile, $15-45^{\circ} \mathrm{C}$ & TAS [1] \\
\hline & Optimum temperature & $30^{\circ} \mathrm{C}$ & NAS \\
\hline & Salinity & $1 \%$ & TAS [1] \\
\hline \multirow[t]{3}{*}{ MIGS-22 } & Oxygen requirement & aerobic & TAS [1] \\
\hline & Carbon source & $\begin{array}{l}\text { glucose, arabinose, mannose, } \mathrm{N} \text {-acetylglucosamine, } \\
\text { and maltose }\end{array}$ & TAS [1] \\
\hline & Energy source & chemoorganotrophic & TAS [1] \\
\hline MIGS-6 & Habitat & cotton compost & TAS [1] \\
\hline MIGS-15 & Biotic relationship & free living & NAS \\
\hline \multirow[t]{3}{*}{ MIGS-14 } & Pathogenicity & non pathogenic & NAS \\
\hline & Biosafety level & 1 & TAS [27] \\
\hline & Isolation & cotton-waste composts & TAS [1] \\
\hline MIGS-4 & Geographic location & South Korea & TAS [1] \\
\hline MIGS-5 & Sample collection time & 2002 & NAS \\
\hline MIGS-4.1 & Latitude & not reported & \\
\hline MIGS-4.2 & Longitude & not reported & \\
\hline MIGS-4.3 & Depth & not reported & \\
\hline MIGS-4.4 & Altitude & not reported & \\
\hline
\end{tabular}

Evidence codes - IDA: Inferred from Direct Assay (first time in publication); TAS: Traceable Author Statement (i.e., a direct report exists in the literature); NAS: Non-traceable Author Statement (i.e., not directly observed for the living, isolated sample, but based on a generally accepted property for the species, or anecdotal evidence). These evidence codes are from of the Gene Ontology project [28]. If the evidence code is IDA, then the property was directly observed by one of the authors or an expert mentioned in the acknowledgements.

\section{Chemotaxonomy}

The fatty acids of strain $4 \mathrm{M} 15^{\mathrm{T}}$ comprise a complex mixture of straight chain saturated and unsaturated acids, together with iso-branched, anteisobranched and hydroxylated acids. The fatty acids comprise iso- $\mathrm{C}_{15: 0}(24.2 \%), \mathrm{C}_{16: 1} \omega 5 \mathrm{c}(2.8 \%), \mathrm{C}_{16: 0}$ (5.6\%), iso- $\mathrm{C}_{15: 0} 3-\mathrm{OH}(2.8 \%)$, iso- $\mathrm{C}_{17: 1} \omega 9 \mathrm{c}(1.4 \%)$, $\mathrm{C}_{16: 0} 3-\mathrm{OH}$ (2.5\%), iso- $\mathrm{C}_{17: 0} 3-\mathrm{OH}(10.5 \%)$ and the summed feature listed in the MIDI Sherlock system as $\mathrm{C}_{16: 1} \omega 7 \mathrm{c}$ and/or iso- $\mathrm{C}_{15: 0} 2-\mathrm{OH}(30.5 \%)$ and iso$\mathrm{C}_{15: 0} 2-\mathrm{OH}$ and/or $\mathrm{C}_{16: 1} \omega 7 \mathrm{c}(15.9 \%)$. These two peaks probably represent $\mathrm{C}_{16: 1} \omega 7 \mathrm{c}(30.5 \%)$ and iso- $\mathrm{C}_{15: 0} 2-\mathrm{OH}(15.9 \%)$ of the fatty acids. The presence of saturated, unsaturated straight chain fatty acids, together with branched chain (largely iso-) normal and 2-OH and 3-OH derivatives is fairly typical of the aerobic members of the Bacteroidetes. The major isoprenoid quinone is menaquinone MK7, a trace amount of menaquinone MK-8 was detected [1]. The polar lipids of L. byssophila have not been determined, but for a number of other taxa, including Rudanella lutea 5715S-11'T, S. linguale DSM 74\%, Larkinella insperata LMG $22510^{\mathrm{T}}$ and some members of the genus Sphingobacterium and Parapedobacter $[29,30]$ the presence of phosphatidylethanolamine as the major (diglyceride based) phospholipid and a number of not further characterized lipids and amino lipids provide useful taxonomic and evolutionary markers [31]. 


\section{Genome sequencing and annotation Genome project history}

This organism was selected for sequencing on the basis of its phylogenetic position [32], and is part of the Genomic Encyclopedia of Bacteria and Archaea project [33]. The genome project is deposited in the
Genomes OnLine Database [19] and the complete genome sequence is deposited in GenBank. Sequencing, finishing and annotation were performed by the DOE Joint Genome Institute (JGI). A summary of the project information is shown in Table 2.

Table 2. Genome sequencing project information

\begin{tabular}{lll}
\hline MIGS ID & Property & Term \\
\hline MIGS-31 & Finishing quality & Finished \\
MIGS-28 & Libraries used & Genomic libraries: one 454 pyrosequence standard library, one 454 \\
MIGS-29 & Sequencing platforms & PE library (11.7 kb insert size); one illumina standard library \\
MIGS-31.2 & Sequencing coverage & 71.4 $\times$ pyrosequence; $105.0 \times$ Illumina \\
MIGS-30 & Assemblers & Newbler version 2.3-PreRelease-10-21-2009-gcc-4.1.2-threads, \\
& phrap, Velvet \\
MIGS-32 & Gene calling method & Prodigal 1.4, GenePRIMP \\
& INSDC ID & CP002305 \\
& Genbank Date of Release & November 12, 2010 \\
& GOLD ID & Gc01535 \\
& NCBI project ID & 38283 \\
& Database: IMG-GEBA & 2503538002 \\
MIGS-13 & Source material identifier & DSM 17132 \\
& Project relevance & Tree of Life, GEBA \\
\hline
\end{tabular}

\section{Growth conditions and DNA isolation}

L. byssophila 4M15T, DSM 17132, was grown in DSMZ medium 545 (Tryptone soya broth, TSB) [34] at $30^{\circ} \mathrm{C}$. DNA was isolated from $0.5-1 \mathrm{~g}$ of cell paste using Qiagen Genomic 500 DNA Kit (Qiagen, Hilden, Germany) following the standard protocol as recommended by the manufacturer with modification st/L for cell lysis as described in Wu et al. [33]. DNA is available through the DNA Bank Network $[35,36]$.

\section{Genome sequencing and assembly}

The genome was sequenced using a combination of Illumina and 454 sequencing platforms. All general aspects of library construction and sequencing can be found at the JGI website [37]. Pyrosequencing reads were assembled using the Newbler assembler version 2.3-PreRelease-10-21-2009-gcc-4.1.2threads (Roche). The initial Newbler assembly consisting of 73 contigs in one scaffold was converted into a phrap assembly by making fake reads from the consensus, collecting the read pairs in the 454 paired end library. Illumina GAii sequencing data (420.0 Mb) was assembled with Velvet [38] and the consensus sequences were shredded into $1.5 \mathrm{~kb}$ overlapped fake reads and assembled together with the 454 data. The 454 draft assembly was based on 237.2 MB 454 draft data and all of the 454 paired end data. Newbler parameters are -consed a 50 -l 350 -g -m -ml 20.

The Phred/Phrap/Consed software package [39] was used for sequence assembly and quality assessment in the following finishing process. After the shotgun stage, reads were assembled with parallel phrap (High Performance Software, LLC). Possible mis-assemblies were corrected with gapResolution [37], Dupfinisher, or sequencing cloned bridging PCR fragments with subcloning or transposon bombing (Epicentre Biotechnologies, Madison, WI) [40]. Gaps between contigs were closed by editing in Consed, by PCR and by Bubble PCR primer walks (J.-F.Chang, unpublished). A total of 195 additional reactions were necessary to close gaps and to raise the quality of the finished sequence. Illumina reads were also used to correct potential base errors and increase consensus quality using a software Polisher developed at JGI [41]. The error rate of the completed genome sequence is less than 1 in 100,000 . Together, the combination of the Illumina and 454 sequencing platforms provided $176.4 \times$ coverage of the ge- 
nome. Final assembly contains $1,209,137$ pyrosequence and 14,794,926 Illumina reads.

\section{Genome annotation}

Genes were identified using Prodigal [42] as part of the Oak Ridge National Laboratory genome annotation pipeline, followed by a round of manual curation using the JGI GenePRIMP pipeline [43]. The predicted CDSs were translated and used to search the National Center for Biotechnology Information (NCBI) nonredundant database, UniProt, TIGRFam, Pfam, PRIAM, KEGG, COG, and InterPro databases. Additional gene prediction analysis and functional annotation was performed within the Integrated Microbial Genomes - Expert Review (IMG-ER) platform [44].

\section{Genome properties}

The genome is 4,059,653 bp long and comprises one circular chromosome with a $40.4 \% \mathrm{G}+\mathrm{C}$ content (Table 3 and Figure 3). Of the 3,666 genes predicted, 3,613 were protein-coding genes, and 53 RNAs; 148 pseudogenes were also identified. The majority of the protein-coding genes (64.8\%) were assigned with a putative function while the remaining ones were annotated as hypothetical proteins. The distribution of genes into COGs functional categories is presented in Table 4.

Table 3. Genome Statistics

\begin{tabular}{lrr}
\hline Attribute & Value & \% of Total \\
\hline Genome size (bp) & $4,059,653$ & $100.00 \%$ \\
DNA coding region (bp) & $3,643,561$ & $89.75 \%$ \\
DNA G+C content (bp) & $1,640,653$ & $40.41 \%$ \\
Number of replicons & 1 & \\
Extrachromosomal elements & 0 & \\
Total genes & 3,666 & $100.00 \%$ \\
RNA genes & 53 & $1.45 \%$ \\
rRNA operons & 1 & \\
Protein-coding genes & 3,613 & $98.55 \%$ \\
Pseudo genes & 148 & $4.04 \%$ \\
Genes with function prediction & 2,375 & $64.78 \%$ \\
Genes in paralog clusters & 502 & $13.69 \%$ \\
Genes assigned to COGs & 2,353 & $64.18 \%$ \\
Genes assigned Pfam domains & 2,618 & $71.41 \%$ \\
Genes with signal peptides & 985 & $26.29 \%$ \\
Genes with transmembrane helices & 711 & $19.39 \%$ \\
CRISPR repeats & 3 & \\
\hline
\end{tabular}

\section{Insights from genome sequence}

The orange color of $L$. byssophila is due to the presence of flexirubin, a pigment consisting of an $\omega$-phenyloctaenic acid chromophore esterified with resorcinol carrying two hydrocarbon chains. Flexirubins are yellow under neutral pH conditions and become red under alkaline conditions. In Flavobacterium johnsoniae a cluster of genes involved in flexirubin synthesis was identified [45], with Fjoh_1102 and Fjoh_1103 having likely roles in the synthesis. Homologs of these genes were also identified in the flexirubin-producing Bacteroidetes Flavobacterium psychrophilum and $C$. hutchinsonii, Fjoh_1102 and Fjoh_1103 are similar to
Pseudomonas aurantiaca darA and $\operatorname{darB}$ which are involved in biosynthesis of the antifungal compound 2-hexyl-5-propyl-alkylresorcinol. In 2009 McBride and colleagues demonstrated the important role of Fjoh_1102 and Fjoh_1103 in flexirubin synthesis by constructing an insertion mutant which was cream colored because of the missing flexirubin [45]. Homologs of Fjoh_1102 and Fjoh_1103 were identified in the genome of $L$. byssophila (Lbys_1508 and Lbys_1509), therefore an important function of these genes in the flexirubin synthesis can be inferred. 


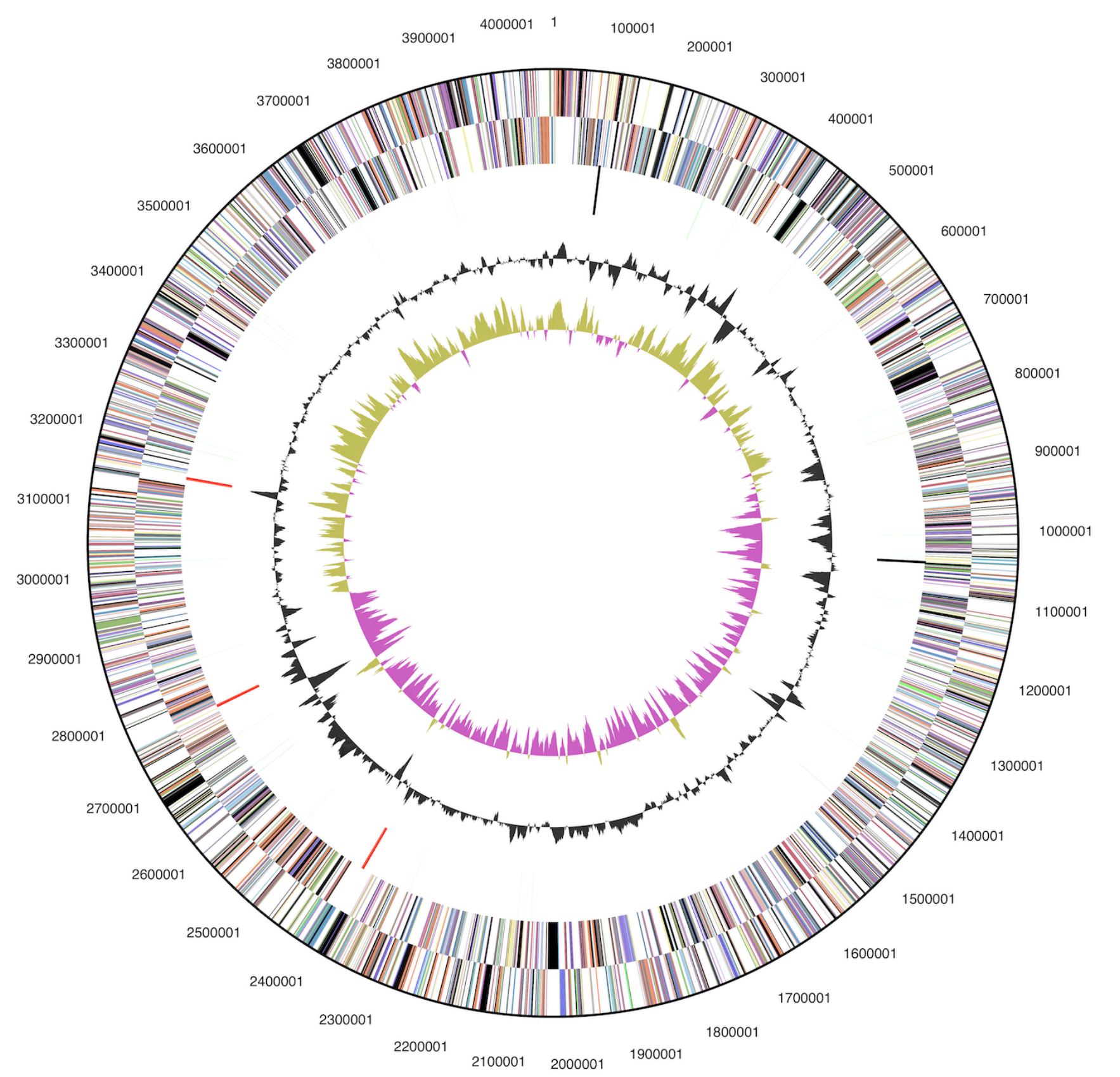

Figure 3. Graphical circular map of the genome. From outside to the center: Genes on forward strand (color by COG categories), Genes on reverse strand (color by COG categories), RNA genes (tRNAs green, rRNAs red, other RNAs black), GC content, GC skew.

Although L. byssophila was isolated from cotton waste, which is mainly composed of cellulose, lignin and hemicellulose, the ability to degrade carboxymethylcellulose and filter paper could not be detected; solely D-cellobiose was assimilated [1]. A closer look into the genome sequence of $L$. byssophila revealed the presence of three genes coding cellobiose or cellulose hydrolyzing enzymes: two $\beta$-glucosidases belonging to glycoside hydrolase family 3 (Lbys_0274, Lbys_1260) and one endoglucanase belonging to glycoside hydrolase family 5 (Lbys_2254). In order to test whether these endoglucanases actively hydrolyze cellulose we carried out a relatively sensitive assay, using hydroxyethylcellulose with a crosslinked azurin as substrate (AZCL-HEC, Megazyme, Ireland). In this test $L$. byssophila was not able to hydrolyze hydroxyethylcellulose (own unpublished data).This observation conforms with the studies done by Weon and colleagues [1]. The finding of three genes probably coding for $\alpha$-amylases (Lbys_0590, Lbys_2307, Lbys_2308) is consistent with the ob- 
served starch degrading ability of L. byssophila [1]. A closer look into the genome sequence revealed four xylan degrading enzymes, three endo-1,4- $\beta$ xylanases belonging to glycoside hydrolase family 10 (Lbys_1832, Lbys_2128, Lbys_2331) and one xylan-1,4- $\beta$-xylosidase belonging glycoside hydrolase family 43 (Lbys_2333). To date the degradation of xylan by L. byssophila was not described, but we could demonstrate the hydrolysis of xylan in a plate assay using xylan with a covalently bound dye as a substrate (remazol brilliant blueD-xylan, Slovak Academy of Science) (own unpublished data).

L. byssophila tested positive for catalase and oxidase [1] The respective genes were identified in the genome sequence. Lbys_1881 encodes a catalase and the genes coding cytochrome $C$ oxidase are localized in the region between Lbys_2190 and Lbys_2195.

Table 4. Number of genes associated with the general COG functional categories

\begin{tabular}{lrrl}
\hline Code & value & \%age & Description \\
\hline J & 152 & 5.9 & Translation, ribosomal structure and biogenesis \\
A & 0 & 0.0 & RNA processing and modification \\
K & 182 & 7.0 & Transcription \\
L & 181 & 7.0 & Replication, recombination and repair \\
B & 1 & 0.0 & Chromatin structure and dynamics \\
D & 23 & 0.9 & Cell cycle control, mitosis and meiosis \\
Y & 0 & 0.0 & Nuclear structure \\
V & 70 & 2.7 & Defense mechanisms \\
T & 142 & 5.5 & Signal transduction mechanisms \\
M & 215 & 8.3 & Cell wall/membrane biogenesis \\
N & 4 & 0.2 & Cell motility \\
Z & 0 & 0.0 & Cytoskeleton \\
W & 0 & 0.0 & Extracellular structures \\
U & 41 & 1.6 & Intracellular trafficking and secretion \\
O & 109 & 4.2 & Posttranslational modification, protein turnover, chaperones \\
C & 142 & 5.5 & Energy production and conversion \\
G & 171 & 6.6 & Carbohydrate transport and metabolism \\
E & 197 & 7.6 & Amino acid transport and metabolism \\
F & 76 & 2.9 & Nucleotide transport and metabolism \\
H & 109 & 4.2 & Coenzyme transport and metabolism \\
I & 90 & 3.5 & Lipid transport and metabolism \\
P & 147 & 5.7 & Inorganic ion transport and metabolism \\
Q & 54 & 2.1 & Secondary metabolites biosynthesis, transport and catabolism \\
R & 321 & 12.4 & General function prediction only \\
S & 164 & 6.3 & Function unknown \\
- & 1,313 & 35.8 & Not in COGs \\
\hline & & &
\end{tabular}

\section{Acknowledgements}

We would like to gratefully acknowledge the help of Helga Pomrenke for growing $L$. byssophila cultures, Susanne Schneider for DNA extraction and quality analysis and Jennifer Gregor for substrate assays (all at DSMZ). This work was performed under the auspices of the US Department of Energy Office of Science, Biological and Environmental Research Program, and by the University of California, Lawrence Berkeley National
Laboratory under contract No. DE-AC02-05CH11231, Lawrence Livermore National Laboratory under Contract No. DE-AC52-07NA27344, and Los Alamos National Laboratory under contract No. DE-AC0206NA25396, UT-Battelle and Oak Ridge National Laboratory under contract DE-AC05-000R22725, as well as German Research Foundation (DFG) INST 599/1-2. 


\section{References}

1. Weon HY, Kim BY, Kwon SW, Park IC, Cha IB, Tindall BJ, Stackebrandt E, Trüper HG, Go SJ. Leadbetterella byssophila gen. nov., sp. nov., isolated from cotton waste composts for the cultivation of oyster mushroom. Int / Syst Evol Microbiol 2005; 55:2297-2302. PubMed doi:10.1099/ijs.0.63741-0

2. Ludwig W, Klenk HP. Overview: a phylogenetic backbone and taxonomic framework for procaryotic systematics. In: Bergey's Manual of Systematic Bacteriology 2001. Boone DR, Castenholz RW, Garrity GM (eds), 2nd edn, vol. 1, pp. 49-65. New York: Springer.

3. Garrity GM, Lilburn TG, Cole JR, Harrison SH, Euzéby J, Tindall BJ. Taxonomic outline of the Bacteria and Archaea, Release 7.7 March 6, 2007. Part 11 - The Bacteria: Phyla

'Planctomycetes', 'Chlamydiae', 'Spirochaetes', 'Fibrobacteres', 'Acidobacteria', 'Bacteroidetes', 'Fusobacteria', 'Verrucomicrobia', 'Dictyoglomi', 'Gemmatimonadetes', and 'Lentisphaerae'. http://www.taxonomicoutline.org/index.php/toba/ article/viewFile/188/220202007.

4. Lail K, Sikorski J, Saunders E, Lapidus A, Glavina Del Rio T, Copeland A, Tice H, Cheng JF, Lucas $\mathrm{S}$, Nolan $\mathrm{M}$, et al. Complete genome sequence of Spirosoma linguale type strain $\left(1^{\mathrm{T}}\right)$. Stand Genomic Sci 2010; 2:176-184. doi:10.4056/sigs.741334

5. Saha P, Chakrabarti T. Emticicia oligotrophica gen. nov., sp. nov., a new member of the family 'Flexibacteraceae', phylum Bacteroidetes. Int J Syst Evol Microbiol 2006; 56:991-995. PubMed doi:10.1099/ijs.0.64086-0

6. Liu QM, Ten LN. YUu HS, Jin FX, Im WT, Lee ST. Emticicia ginsengisoli sp. nov., a species of the family 'Flexibacteraceae' isolated from soil of a ginseng field. Int I Syst Evol Microbiol 2008; 58:1100-1105. PubMed doi:10.1099/ijs.0.65386$\underline{0}$

7. Chun J, Lee JH, Jung Y, Kim M, Kim S, Kim BK, Lim YW. EzTaxon: a web-based tool for the identification of prokaryotes based on $16 \mathrm{~S}$ ribosomal RNA gene sequences. Int I Syst Evol Microbiol 2007; 57:2259-2261. PubMed doi:10.1099/ijs.0.64915-0

8. Krzemieniewska H. Contribution à l'étude du genre Cytophaga (Winogradsky). Arch Mikrobiol 1933; 4:394-408. doi:10.1007/BF00407552

9. Táncsics A, Kéki Z, Márialigeti K, Schumann P, Toth EM. Siphonobacter aquaeclarae gen. nov., sp. nov., a novel member of the family
'Flexibacteraceae', phylum Bacteroidetes. Int J Syst Evol Microbiol 2010; 60:2567-2571. PubMed doi:10.1099/ijs.0.019398-0

10. DeSantis TZ, Hugenholtz P, Larsen N, Rojas M, Brodie EL, Keller K, Huber T, Dalevi D, Hu P, Andersen GL. Greengenes, a Chimera-Checked $16 \mathrm{~S}$ rRNA Gene Database and Workbench Compatible with ARB. Appl Environ Microbiol 2006; 72:5069-5072. PubMed doi:10.1128/AEM.03006-05

11. Porter MF. An algorithm for suffix stripping. Program: electronic library and information systems 1980; 14:130-137.

12. Li K, Guan W, Wei G, Liu B, Xu J, Zhao L, Thang $\mathrm{Y}$. Phylogenetic analysis of intestinal bacteria in the Chinese mitten crab (Eriocheir sinensis). J Appl Microbiol 2007; 103:675-682. PubMed doi:10.1111/j.1365-2672.2007.03295.x

13. Li AJ, Li XY. Selective sludge discharge as the determining factor in SBR aerobic granulation: $\mathrm{Nu}$ merical modelling and experimental verification. Water Res 2009; 43:3387-3396. PubMed doi:10.1016/j.watres.2009.05.004

14. Haichar FZ, Marol C, Berge O, Rangel-Castro Jl, Prosser JI, Balesdent J, Heulin T, Achouak W. Plant host habitat and root exudates soil bacterial community structure. ISME J 2008; 2:1221-1230. PubMed doi:10.1038/ismej.2008.80

15. Lee C, Grasso C, Sharlow MF. Multiple sequence alignment using partial order graphs. Bioinformatics 2002; 18:452-464. PubMed doi:10.1093/bioinformatics/18.3.452

16. Castresana J. Selection of conserved blocks from multiple alignments for their use in phylogenetic analysis. Mol Biol Evol 2000; 17:540-552. PubMed

17. Stamatakis A, Hoover P, Rougemont J. A rapid bootstrap algorithm for the RAxML web servers. Syst Biol 2008; 57:758-771. PubMed doi:10.1080/10635150802429642

18. Pattengale ND, Alipour M, Bininda-Emonds ORP, Moret BME, Stamatakis A. How Many Bootstrap Replicates Are Necessary? Lect Notes Comput Sci 2009; 5541:184-200. doi:10.1007/978-3-64202008-7_13

19. Liolios K, Chen IM, Mavromatis K, Tavernarakis N, Kyrpides NC. The Genomes On Line Database (GOLD) in 2009: status of genomic and metagenomic projects and their associated metadata. 
Nucleic Acids Res 2010; 38:D346-D354. PubMed doi:10.1093/nar/gkp848

20. Xie G, Bruce DC, Challacombe JF, Chertkov O, Detter JC, Gilna P, Han CS, Lucas S, Misra M, Myers GL, et al. Genome sequence of the cellulolytic gliding bacterium Cytophaga hutchinsonii. Appl Environ Microbiol 2007; 73:3536-3546. PubMed doi:10.1128/AEM.00225-07

21. Lang E, Lapidus A, Chertkov O, Brettin T, Detter JC, Han C, Copeland A, Glavina Del Rio T, Nolan $\mathrm{M}$, Chen $\mathrm{F}$, et al. Complete genome sequence of Dyadobacter fermentans type strain (NS114 $)$. Stand Genomic Sci 2009; 1:133-140. doi:10.4056/sigs.19262

22. Field D, Garrity G, Gray T, Morrison N, Selengut J, Sterk P, Tatusova T, Thomson N, Allen MJ, Angiuoli SV, et al. The minimum information about a genome sequence (MIGS) specification. Nat Biotechnol 2008; 26:541-547. PubMed doi:10.1038/nbt1360

23. Woese CR, Kandler O, Wheelis ML. Towards a natural system of organisms. Proposal for the domains Archaea and Bacteria. Proc Natl Acad Sci USA 1990; 87:4576-4579. PubMed doi:10.1073/pnas.87.12.4576

24. Garrity GM, Holt J. Taxonomic outline of the Archaea and Bacteria. In: Bergey's Manual of Systematic Bacteriology, $2^{\text {nd }}$ ed. vol. 1. The Archaea, Deeply Branching and Phototrophic Bacteria. Garrity GM, Boone DR and Castenholz RW (eds). 2001; 155-166.

25. Skerman VBD, McGowan V, Sneath PHA. Approved Lists of Bacterial Names. Int / Syst Bacteriol 1980; 30:225-420. doi:10.1099/0020771330-1-225

26. Stanier RY. Studies on the Cytophagas. / Bacteriol 1940; 40:619-635. PubMed

27. BAuA. Classification of bacteria and archaea in risk groups. Bundesanstalt für Arbeitsschutz und Arbeitsmedizin, Germany. TRBA 2005; 466:84.

28. Ashburner M, Ball CA, Blake JA, Botstein D, Butler H, Cherry JM, Davis AP, Dolinski K, Dwight SS, Eppig JT, et al. Gene ontology: tool for the unification of biology. The Gene Ontology Consortium. Nat Genet 2000; 25:25-29. PubMed doi:10.1038/75556

29. Kim SJ, Weon HY, Kim YS, Yoo SH, Kim BY, Anandham R, Kwon SW. Parapedobacter luteus sp. nov. and Parapedobacter composti sp. nov., isolated from cotton waste compost. Int J Syst Evol
Microbiol 2010; 60:1849-1853. PubMed

doi:10.1099/ijs.0.013318-0

30. Naka T, Fujiwara N, Yano I, Maeda S, Doe M, Minamino M, Ikeda N, Kato Y, Watabe K, Kumazawa $Y$, et al. Structural analysis of sphingophospholipids derived from Sphingobacterium spiritivorum, the type species of genus Sphingobacterium. Biochim Biophys Acta 2003; 1635:83-92. PubMed

31. Weon HY, Noh HJ, Son JA, Jang HB, Kim BY, Kwon SW, Stackebrandt E. Rudanella lutea gen. nov., sp. nov., isolated from an air sample in Korea. Int J Syst Evol Microbiol 2008; 58:474-478. PubMed doi:10.1099/ijs.0.65358-0

32. Klenk HP, Goeker M. En route to a genome-based classification of Archaea and Bacteria? Syst Appl Microbiol 2010; 33:175-182. PubMed doi:10.1016/j.syapm.2010.03.003

33. Wu D, Hugenholtz $P$, Mavromatis K, Pukall R, Dalin E, Ivanova NN, Kunin V, Goodwin L, Wu $M$, Tindall BJ, et al. A phylogeny-driven genomic encyclopaedia of Bacteria and Archaea. Nature 2009; 462:1056-1060. PubMed doi:10.1038/nature08656

34. List of growth media used at DSMZ: http://www.dsmz.de/microorganisms/media_list.p hp

35. DNA bank Network. http://www.dnabanknetwork.org.

36. Gemeinholzer B, Dröge G, Zetzsche H, Haszprunar G, Klenk HP, Güntsch A, Berendsohn WG, Wägele JW. The DNA Bank Network: the start from a German initiative. Biopreservation and Biobanking (In press).

37. DOE Joint Genome Institute. http://www.jgi.doe.gov/

38. Zerbino DR, Birney E. Velvet: algorithms for de novo short read assembly using de Bruijn graphs. Genome Res 2008; 18:821-829. PubMed doi:10.1101/gr.074492.107

39. Phrap and Phred for Windows. MacOS, Linux, and Unix. http://www.phrap.com

40. Han C, Chain P. Finishing repeat regions automatically with Dupfinisher. In: Proceeding of the 2006 international conference on bioinformatics \& computational biology. HR Arabnia \& H Valafar (eds), CSREA Press. June 26-29, 2006; 141146.

41. Lapidus A, LaButti K, Foster B, Lowry S, Trong S, Goltsman E. POLISHER: An effective tool for us- 
ing ultra short reads in microbial genome assembly and finishing. AGBT, Marco Island, FL, 2008.

42. Hyatt D, Chen GL, LoCascio PF, Land ML, Larimer FW, Hauser LJ. Prodigal: prokaryotic gene recognition and translation initiation site identification. BMC Bioinformatics 2010; 11:119. PubMed doi:10.1186/1471-2105-11-119

43. Pati A, Ivanova NN, Mikhailova N, Ovchinnikova G, Hooper SD, Lykidis A, Kyrpides NC. GenePRIMP: a gene prediction improvement pipeline for prokaryotic genomes. Nat Methods 2010; 7:455-457. PubMed doi:10.1038/nmeth.1457
44. Markowitz VM, Ivanova NN, Chen IMA, Chu K, Kyrpides NC. IMG ER: a system for microbial genome annotation expert review and curation. Bioinformatics 2009; 25:2271-2278. PubMed doi:10.1093/bioinformatics/btp393

45. McBride MJ, Xie G, Martens EC, Lapidus A, Henrissat B, Rhodes RG, Goltsman E, Wang W, Xu J, Hunnicutt DW, et al. Novel features of the polysaccharide-digesting gliding bacterium Flavobacterium johnsoniae as revealed by genome sequence analysis. Appl Environ Microbiol 2009; 75:6864-6875. PubMed doi:10.1128/AEM.01495-09 